\title{
A Study on the Clinician Probed for Issues in Relation to Police Information
}

\author{
${ }^{1}$ Surendra K Sharma, ${ }^{2}$ Rajesh Kumar
}

\section{ABSTRACT}

Background: Police information (PI) is a clinician's legal duty in medicolegal case (MLC). But informing late or not informing or informing inadequately or deceptively is questionable and debatable. Mistake, glitches, and flaws in police information do embarrass clinicians. The embarrassments of the clinician usually go unreported. This is a study on real mistakes and embarrassments in which clinician faced investigators ire while explaining one's stand in favor or against considering the MLC.

Aim and objectives: To study the expectation and demand of $\mathrm{PI}$. It is also to know and identify how embarrassments took place, who embarrassed and who tried to hide the reality.

Materials and methods: A retrospective study of cases with respect to patient's presentation vis-à-vis clinician's role and investigational expectations and ultimate outcome. Results Witch hunting in self-inflicted injury (SII) and self-suffered injuries (SSI) makes PI crucial. Probe unearth conspiracy and the clinician's role. It was too difficult for a clinician to appear genuine where he looked to a part of the conspiracy. Mistakes in deciding the issue of the MLC or nonmedicolegal NMLC usually are due to deceptive tampered background story, false implicating tendencies.

Conclusion: SSI of the type of firearm injury, sharp weapon injury and digital fracture are as much a headache for the clinician as for the investigators. Consequences of misinformation affect clinician not only as an individual but also affect the profession. The message should be clear and loud that the witch hunt should not start from the clinician's information to the police. The obsession to get the things manipulated makes clinician's performance suspicious. Exclusion of MLC from the nonmedicolegal case (NMLC) was not as easy as it looked. Clinicians need to act proactively. Interested parties might oppose a proactive role in sending information.

Keywords: Medicolegal case, Non-medicolegal case, Police information, Self-inflicted injury, Self-suffered injury.

How to cite this article: Sharma SK, Kumar R. A Study on the Clinician Probed for Issues in Relation to Police Information. J Med Acad, 2018;1(2):86-90.

Source of support: Nil

Conflict of interest: None

${ }^{1}$ Professor and Head, ${ }^{2}$ Assistant Professor

1,2Department of Forensic Medicine and Toxicology, Army College of Medical Sciences, New Delhi, India

Corresponding Author: Surendra K Sharma, Professor and Head, Department of Forensic Medicine and Toxicology, Army College of Medical Sciences, New Delhi, India, e-mail: drsharma1951@gmail.com

\section{INTRODUCTION}

Sending police information (PI) is one of the routine medicolegal practices of the clinicians. PI helps the investigator know about criminality if any. Such PI played a pivotal role in understanding and solving criminal puzzles. Functioning of our criminal justice system is such that the truth can't remain hidden for long and is exposed ultimately. Sooner or later truth that comes out confronts PI. Truth exposed at times was so different from PI that the PI was adjudged as to be deliberately confusing or misleading the investigation. It might appear to have begun the witch hunt. Question is whether PI had betrayed the investigator or the clinician was being betrayed. In common language what is bad-misleading others or being misled or both. Obviously both but why does that keep occurring is one issue.

What is the incidence of PI-related controversies? How many clinicians had been grilled for informing police wrongly or carelessly? How many of the clinicians had faced the humiliation of being quizzed? The answer to all these queries needs to be learned in order to prevent repeating the same mistakes.

Though it is almost impossible to have access to any such national or institutional data it would be improper to assume that PI related controversies don't occur. In the absence of authenticated data, the only method left is by gathering experiences of the affected clinicians and the investigators.

The phenomenon of knowingly and intentionally injuring oneself (self-infliction) is reported in forensic medicine textbooks. ${ }^{1-4}$ But the phenomenon of agreeing to get injured by someone else (self-suffered) though well-recognized in legal practice is yet to be reported in forensic textbooks. Victims of such injuries are seen to be mis-presenting before the clinicians with fake stories of assault and are a headache to the clinician as well as for the investigator. Bishambar's castration in police custody in 1992 in district Rewadi in Haryana is not only the biggest classical example of the self-inflicted genital injury, but a reminder to the turmoil clinicians and the concerned officials had to face. ${ }^{5-8}$ No one was in favor, rather were against the theory of self-infliction. One could believe the truth that Bishambar had severed his testes knowingly only when the honorable court ruled his injury was self-inflicted. ${ }^{9}$ The case may be too old to be considered and brushed aside by few, but it is still relevant. Nothing has changed neither 
false implicating tendencies of the people nor the clinician's risks and inconvenience. To derive personal benefit resorting to self-infliction has been one of the methods. It is well reported. ${ }^{10-13}$

PI in such situations runs the risk of appearing to be a conduit to bring about a criminal charge against an innocent. Imagine a clinician doubting the statement of the injured when the patient tells him that the injury he had suffered was as a result of an assault by a blade or a knife or a kutta. Why should a clinician suspect his story or why should an injured, should willingly go for another injury is better known to an investigator rather than to a common man.

The phenomenon of self-suffered digital fracture is also reported. ${ }^{14}$ Depending upon the manner in which the digital fracture was acquired, two patterns of selfsuffered digital fracture are reported. One, the pattern of multiple small pieces of the terminal phalanx of the little finger (comminuted fracture) acquired by carefully striking on a padded and anesthetized finger. The other was that of the complete fracture of the shaft of the phalanx with characteristic angulation where the fracture had been caused by putting a bottle around the finger and giving a sudden jerk. Tenderness and the fracture deformity were so glaring that it could not be missed during the examination. The victim's complaints against the clinician to have missed the newly acquired injury was a lie. Explains acquiring such fractures by the twisting of his hand in a scuffle or on being hit by a lathi was another fake.

There is thus some PI which has embarrassed both the sender and the recipients of the information. That raises a question as to how and when should PI be sent so that a clinician does not appear incredible. Those clinicians who had to face the investigators or court's heat belong to three categories.

Genuine looking fake story of assault. Assault theory was clear but finally turned out to be fake, e.g., person tells someone shot and he suffered firearm injury on his right arm. His seeking prosecution of the accused of an attempt to murder $\mathrm{u} / \mathrm{s} 307$ of IPC remains a matter under investigation. It took many months for the police to find out that the injury was self-inflicted. Another example in which the injured came to the hospital telling the cops had cut his testes. Though the cops had been prosecuted for castrating the injured but the honorable court ruled the injury was self-inflicted. In both these cases during the investigation, PI remained under the scanner. Presentation of the patient appeared so convincing to the clinician that it was too difficult or highly improbable for the clinician to doubt.

Visibly doubtful assault theory, e.g., there were multiple small superficial parallel typical self-inflicted scratch abrasions on the front of one's chest and front and sides of arms. Clinicians had reasons to believe that abrasions were self-inflicted. In another example, fracture deformity was suggestive of its being a self-suffered digital fracture. Question is if a clinician was in this category, was he supposed to inform police with or without expressing his suspicion of self-infliction or self-suffering. Doing so will not clinician appear to be acting beyond one's area of responsibility. Is clinician supposed to remain mum on the issue of the manner of causation till the time he is asked?

Genuine looking manufactured assault theory. Clinician knew that the assault theory was engineered/ manufactured. PI was being sent even in such cases because the clinicians have been taught to send PI even though the injury was self-inflicted or self-suffered. If the manner of causation was none of his concern then why was clinician blamed for direct or indirect participation in sponsoring the orchestrated event of a fake assault?

\section{AIMS AND OBJECTIVES}

To study the expectation and demand of PI. It is also to know and identify how embarrassments took place, who embarrassed and who tried to hide the reality.

\section{MATERIALS AND METHODS}

Cases in which clinician faced investigator's or court's heat are studied. Cases under study are those in which a clinician felt he should not have been questioned but was. Cases in which a clinician was supposed to appear before the magistrate to explain one's stand were included.

Information gathered from the experiences of the affected clinicians and the investigators. Has been tabulated, evaluated and analyzed to find out what was the truth in a particular situation, how the truth was exposed and who was hiding the truth ultimately, how the dust was settled? Such controversies are a matter of study.

\section{RESULTS}

The clinician was probed for informing late or not informing or informing inadequately or deceptively. Clinicians were made to explain his stand much after the actual occurrence. Reasons for being quizzed clinician comes to know only at the time of questioning. Being suspected/questioned/grilled is the biggest ever unpleasant and unforgettable personal experience for a clinician.

- Cases 1 and 2 (Table 1) indicated deceptive presentation of the injured and by the cops.

- PI in cases 3 and 4 (Table 1) appeared to be deceptive but was not. Clinician actually did not have access to reality. PI related controversies are observed to be a perceptional issue between people of two different domains 
Table 1: Concise background about the presentation of the nine medicolegal cases

\begin{tabular}{|c|c|c|c|c|c|}
\hline \multicolumn{6}{|c|}{ Background and outcome of the cases } \\
\hline Case no. & Case details & Clinician's inference & Effect on clinician & Impact on the case & Truth exposed \\
\hline 1 & $\begin{array}{l}\text { Fresh bleeding lacerated } \\
\text { wound on the middle back } \\
\text { of the left leg of a boy } \\
\text { was said to have been } \\
\text { sustained on falling from } \\
\text { a cycle. }\end{array}$ & $\begin{array}{l}\text { Firearm entry wound } \\
\text { with Bullet shadow } \\
\text { observed in the X-ray } \\
\text { of his left leg }\end{array}$ & Clinician felt misled & $\begin{array}{l}\text { Cops hunting for } \\
\text { him arrived in the } \\
\text { hospital and took } \\
\text { him into custody }\end{array}$ & $\begin{array}{l}\text { Deceptive } \\
\text { presentation by } \\
\text { the injured person }\end{array}$ \\
\hline 2 & $\begin{array}{l}\text { Forty-five years old } \\
\text { deceased had nick } \\
\text { and a contusion on the } \\
\text { middle front on his neck. } \\
\text { Police had registered a } \\
\text { case of murder. Cops } \\
\text { expected clinician to } \\
\text { derive inference from the } \\
\text { injuries. Death by stab } \\
\text { and strangulation was } \\
\text { expected. Component of } \\
\text { suicidal hanging was not } \\
\text { in the sight. }\end{array}$ & $\begin{array}{l}\text { Two injuries on the } \\
\text { neck } \\
\text { One sharp weapon } \\
\text { injury } \\
\text { One contusion } \\
\text { Blood soiling on the } \\
\text { upper front of his vests } \\
\text { Component of suicidal } \\
\text { hanging was in the } \\
\text { sight after crime scene } \\
\text { visit and circumstantial } \\
\text { evidence }\end{array}$ & $\begin{array}{l}\text { The clinician was } \\
\text { misled to derive } \\
\text { inference from the } \\
\text { injuries. }\end{array}$ & $\begin{array}{l}\text { Death was due to } \\
\text { hanging. } \\
\text { Hanging was } \\
\text { suicidal. } \\
\text { Ligature mark was } \\
\text { atypical } \\
\text { Sharp weapon } \\
\text { injury was a post- } \\
\text { mortem }\end{array}$ & $\begin{array}{l}\text { Deceptive } \\
\text { presentation by } \\
\text { the police }\end{array}$ \\
\hline 3 & $\begin{array}{l}\text { A } 25 \text {-year-old injured } \\
\text { person was brought for an } \\
\text { injury on the head with the }\end{array}$ & \multirow{3}{*}{$\begin{array}{l}\text { Head injury with a fresh } \\
\text { bleeding laceration on } \\
\text { the head }\end{array}$} & \multirow{3}{*}{$\begin{array}{l}\text { NMLC and not } \\
\text { sending PI was } \\
\text { questioned and } \\
\text { clinician had to } \\
\text { justify his stand }\end{array}$} & $\begin{array}{l}\text { Trial u/s } 302 \text { on } \\
\text { being hit by a brick } \\
\text { and lathi blows }\end{array}$ & \multirow{3}{*}{$\begin{array}{l}\text { Deceptive } \\
\text { presentation by } \\
\text { the injured person }\end{array}$} \\
\hline & $\begin{array}{l}\text { history of brick falling on } \\
\text { his head accidentally. }\end{array}$ & & & & \\
\hline 4 & $\begin{array}{l}\text { A 52-year-old injured } \\
\text { person allegedly getting } \\
\text { injured on falling down } \\
\text { from the roof. He was } \\
\text { under the influence of } \\
\text { alcohol. }\end{array}$ & & & $\begin{array}{l}\text { Trial u/s } 302 \text { on } \\
\text { being pushed from } \\
\text { the roof }\end{array}$ & \\
\hline 5 & $\begin{array}{l}\text { PI was about someone } \\
\text { being brought dead (BID) }\end{array}$ & $\begin{array}{l}\text { Death was due to } \\
\text { firearm injury }\end{array}$ & & \multirow[t]{2}{*}{$\begin{array}{l}\text { Self-suffered } \\
\text { injuries }\end{array}$} & \multirow{6}{*}{$\begin{array}{l}\text { Criminal } \\
\text { conspiracy of } \\
\text { the injured (SSI) } \\
\text { proved }\end{array}$} \\
\hline 6 & $\begin{array}{l}\text { PI of the sharp weapon } \\
\text { injury }\end{array}$ & $\begin{array}{l}\text { Injured suffered sharp } \\
\text { weapon injury-incised } \\
\text { wound. }\end{array}$ & $\begin{array}{l}\text { Clinician appeared } \\
\text { to have given } \\
\text { leeway }\end{array}$ & & \\
\hline 7 & $\begin{array}{l}\text { PI of the sharp weapon } \\
\text { injury }\end{array}$ & $\begin{array}{l}\text { Patient had multiple } \\
\text { stabs on the chest. }\end{array}$ & & Trial u/s 302 & \\
\hline 8 & & $\begin{array}{l}\text { Commuted fracture of } \\
\text { the terminal phalanx }\end{array}$ & \multirow{3}{*}{$\begin{array}{l}\text { Re-examination } \\
\text { requested blaming } \\
\text { the clinician for } \\
\text { missing the injury }\end{array}$} & \multirow{3}{*}{$\begin{array}{l}\text { FIR registered had } \\
\text { to be canceled }\end{array}$} & \\
\hline & PI being injured in the & $\begin{array}{l}\text { of the left-hand index } \\
\text { finger }\end{array}$ & & & \\
\hline 9 & & $\begin{array}{l}\text { Fracture deformity of } \\
\text { the proximal phalanx of } \\
\text { the left little finger }\end{array}$ & & & \\
\hline
\end{tabular}

- Clinician's PI backfired for giving leeway to victim of SSI (5-9) (Table 1) got exposed when investigators made clinicians and the injured sit face to face.

- SSI suffers from the jurisdictional issue. SSI is observed to be such a complicated issue that is ultimately decided by the investigators or the courts. Crime justice system took a few weeks, months and even year to uncover the fact.

- The first message that emerges is PI is crucial. Witch hunting should not start from the clinician's information to the police.
- The patient had their compulsions to make deceptive presentations in SSI.

\section{DISCUSSION}

The concept of PI has been described u/s 39 of Cr. PC. Like a common man clinician too owes a duty to inform police about the suspicion of criminality if he ever comes across during the course of practice. In a way, PI is clinicians' legal duty. Matter of informing the police is crucial, and the concept of PI can't be loosely implemented for the following reasons. 
- Omission to inform police is punishable $\mathrm{u} / \mathrm{s} 176$ IPC.

- There is also a provision of punishment for criminal conspiracy $\mathrm{u} / \mathrm{s} 120 \mathrm{~B}$ of IPC.

- Causing disappearance of evidence or giving false information to screen offender is punishable $\mathrm{u} / \mathrm{s} 201$ IPC

- Intentional omission to give information of an offense is an offense $u / s 202$ IPC.

- Giving false information constitutes an offense $\mathrm{u} / \mathrm{s}$ 203 of IPC

- Furnishing false information makes it an offense $\mathrm{u} / \mathrm{s}$ 177 IPC

- Giving false information with the intent to cause public servant to use his lawful power to the injury of another person is also an offense $\mathrm{u} / \mathrm{s} 182$ IPC PIis processed by the police. The objectives of processing the PI was to probe the suspicion of foul play. The results of processing the PI occasionally impacts clinicians too. The cases in which clinician's role appeared suspicious can be identified in two groups. One in which clinician did not send PI. The issue in this group is why clinician was not able to inform. Did he not have access to reality? The second group is in which clinician had informed, but the issue here is why PI was late or in a manner that started the witch hunt.

Cases 1 and 2 are the two cases in which the clinician was at the receiving end. Misguiding by theinjured in case 1 was as surprising as was it in case 2 . Injured concealed the real story of being involved in a shooting incident in case 1. In case 2 cops had concealed the real story of hanging but presented their case to make use of postmortem injury as antemortem.

\section{Group 1 (Narrow Escape)}

Basically, group 1 revolves around clinician's judgment of MLC versus NMLC. An MLC can not be treated as that of NMLC. Sometimes a case starts as NMLC but later on gets converted into MLC. PI comes underscan when MLC is contested to be that of NMLC. Medical woes start when the clinician was summoned in the trial under the suspicion that clinician had knowingly converted an MLC into NMLC. Defense counsel wanted to use PI as a tool to prove his point. The clinician is supposed to explain one's stand on the issue of MLC/NMLC. The clinician is to explain why the police were not informed.

In courtroom showing written signed a statement of the injured in his own handwriting (cases 3 and 4) that his condition was subsequent to say being kicked by his own buffalo or brick falling on his head qualifies the case to be treated as an NMLC. Imagine clinician's stand if such record wasn't there. Also, imagine if the court was not satisfied results could have gone against the clinician.

\section{Group 2 (Witch Hunt)}

Majority of clinicians know about self-inflicted injury (SII) however about $90 \%$ were unaware of self-suffered injuries (SSI). Because of their ignorance, they are nudged into controversy.

PI in SII and SSI is not simple. PI in case 5 is one such story. PI of a BID due to firearm injury began the story of killing. While processing PI investigators appeared to had no issue about the killing or the use of a weapon of the shotgun; smooth bore firearm ammunition. The main issue of the investigator was that the alleged killer was fake. To reach the real killer cops interrogated the family members of the deceased. They could no longer conceal the secret with them. The real story was different. In order to falsely implicate someone, they intended to get 3-4 discreet pellet injury somewhere on his legs or feet they had hired a shooter. The shooter failed to perform as per the contract. Shot misfired and proved to be fatal as it hit him on the face and chest too. They feared non-acceptance of their story in the police station. So, they had an understanding between the clinician in a district level general hospital that they will bring the injured with pellet injury to him and the clinician would send the PI. Clinician did not realize the consequences of PI as per commitment clinician expected the person to be brought as an injured state but was brought dead. PI instead of being that of section 307 IPC became that of 302 of IPC. Clinician's partnership in the criminal conspiracy was thus exposed.

PI in case 6 was also that of SSI. Presence of the self-suffered sharp weapon injury on the persons of both the sides brought embarrassment to the clinician. Cross-case of an attempt to murder $\mathrm{u} / \mathrm{s} 307$ of IPC was based on the sharp weapon injuries. The use of a sharp weapon in the scuffle appeared to lie to the investigators. The real story was that one side had acquired the sharp weapon injury to bring an accusation against the other. The other party finding himself implicated decided to go the same way. The second party too acquired a similar sharp weapon injury. Concerned clinician initially pleaded ignorance but being confronted with both the injured parties exposed his involvement in the causation of injuries.

In case 7 according to the PI death had taken place in the hospital and was due to due stab injury. Of the two stabs the dead suffered-one was on the front and the other on the back of the chest. The cop' s major issue appeared to be the delay in PI. Probing 6 hours delay in receiving the PI clinician's reaction was that case initially appeared to him as NMLC. History of sustaining an injury during a fall on the knife while hanging a picture on the wall. The family members version was they were 
known to the clinician. In view of the ongoing negotiations to reconcile, they had requested clinician to delay the PI, and he did oblige. PI became essentiality when patient's condition deteriorated unexpectedly. Clinician's lie was exposed. The clinician was embarrassing himself by resorting to lies.

\section{Leeway}

PI continues to be a debatable issue in SII and SSI. Radiologist reporting "pellets" as multiple small radio-opaque spherical shadows or reporting "bullet" in place of single radioopaque shadow is an example of the obfuscator effect of the X-ray reporting. A clear report will certainly facilitate understanding. Similarly, while reporting digital fracture, radiologists instead of mentioning "fracture" alone if a comment on the type of fracture, number of fragments, type of displacement and angulation vis-a-vis the manner of causation will prevent the leeway being extracted from the X-ray reporting in the cases of SSI.

\section{CONCLUSION}

\section{Clinician's Ordeal in Self-inflicted and Self-suffered Injuries}

The clinician should not appear to be a conduit in bringing about or supporting the criminality unnecessarily. But knowingly or unknowingly, consciously or unconsciously that happens. PI should also not seem to be concealing or hiding the truth to screen the offender. Clinician can not afford to be evasive and not cooperating with the investigator.

SII and SSI continue to be a menace not only for the person at the risk of false implication but also for the clinician, hospital administration and the investigators. The victim of SII and that of SSI had greater leeway. He gets the benefit from all sides. Obstructing his being benefited through PI, administrator's or courts order for his examination and $\mathrm{X}$-ray reporting seems to be too difficult to be dealt with. On the issue of cleaning the mess, the answer would be a mess should be cleared by those who create it.

\section{Lessons}

- Clinicians must understand that the concept of PI should not appear to be loosely implemented.

- Victim of SII and SSI is miscreant and seeks leeway in a variety of ways from clinicians.

- Edited version of PI creates doubt to investigators.

- Difficulties in the identification of MLC shall be there. The problem can be minimized by a written and signed statement of the injured and that of the witnesses.

\section{REFERENCES}

1. Dimaio VJ, Dimaio D. Forensic pathology. Second Edition. USA: CRC Press, 2001.

2. Saukko P, Knight B. Knight's forensic pathology. Third Edition. Great Britain: Edward Arnold Ltd, 2004.

3. Dimaio VJ. Gunshot wounds: practical aspects of firearms, Ballistics, and Forensic Techniques, Third Edition. USA: CRC Press, 2015.

4. Aggrawal A. Text book of forensic medicine \& toxicology. first Edition. Delhi: Avichal publishing company, 2016.

5. Khair T. Haryana officials tight lipped as castrated youth lies in agony. Delhi: Times of India. 1992 Oct 23.

6. Khair T. Youth was tortured says minister. Delhi: Times of India. 1992 Oct 27.

7. Khair T. No action yet in Rewari torture case. Delhi: Times of India 1992 Oct 28.

8. Khair T. Castration case in SC for damages. Delhi: Times of India 1992 Nov 04.

9. Additional Sessions Judge. Verdict in the Court of Virender singh. Rewari: Session Case No. 57 of 1993. 1995 Dec 07.

10. Ahuja SK. Gurgaon Cab killer tries to cut his throat in jail: overpowered. Delhi: HT Metro. 1995 Nov 20.

11. Catalano G, Morejon M, Alberts VA, Catalano MC. Report of a case of male genital self-mutilation and review of the literature, with special emphasis on the effects of the media. J Sex Marital Ther. 1996 Spring22(1):35-46.

12. Nerli RB, Ravish IR, Amarkhed SS, Manoranjan UD, Prabha V, Koura A. Genital self-mutilation in nonpsychotic heterosexual males: Case report of two cases. Indian J Psychiatry. 2008 Oct-Dec;50(4):285-287.

13. Eke N. Genital self-mutilation: there is no method in this madness. BJU International. 2001 Dec;85(3):295-298.

14. Sharma SK, Bhardwaj S. Digital Fracture-Forensic Viewpoint. Ind J Radiol Imag. 1991 May;1:57-60. 